\title{
El pensamiento político de Octavio Paz y Mario Vargas Llosa: América Latina en el mundo polarizado
}

Germán Alburquerque F.*

Resumen: Este artículo estudia el pensamiento de los escritores latinoamericanos Octavio Paz y Mario Vargas Llosa a la luz de los procesos políticos más decisivos de la segunda mitad del siglo XX: la Guerra Fría, la lucha del Tercer Mundo y, en el plano continental, el ciclo revolucionario, con sus éxitos y fracasos. Se analiza su pensamiento - y también su acción - con el propósito de constatar, primero, la globalización de los intelectuales latinoamericanos, y segundo, la singularidad de las ideas de ambos escritores, que muchas veces fueron contrarias a las del campo intelectual en general.

Palabras clave: Octavio Paz. Mario Vargas Llosa. Intelectuales latinoamericanos. Pensamiento latinoamericano. Guerra Fría.

\section{Introducción}

Los intelectuales latinoamericanos, desde el siglo XIX, han elaborado una reflexión que no se ha limitado a sus respectivos países sino que se ha hecho extensiva a todo el continente. $Y$ en ello ha sido decisivo, seguramente, el hecho de haber pertenecido,

\footnotetext{
"Magíster en Estudios Latinoamericanos, Universidad de Chile. Doctor en Historia, Universidad Católica de Chile. Correo electrónico: galburqu@uc.cl.
} 
la mayoría de sus naciones, a un tronco común, el imperio español. ${ }^{1}$ Es por eso que desde la temprana república nuestros pensadores se cuestionaron por el continente en su conjunto, por el mejor modo de enfrentar los problemas comunes y por la posibilidad de integrarse para mitigar tales problemas. Paralelamente, dieron vida a una profusa circulación internacional, viajando y conociendo los países hermanos y relacionándose con sus pares de esos países. También nuestros intelectuales mantuvieron un diálogo fluido con los estados centrales, aquellos donde nacían las ideas que más tarde eran adoptadas y adaptadas a la realidad local. Francia, Inglaterra, Estados Unidos y, lógicamente, España, fueron pues destinos frecuentes y objetos recurrentes de su reflexión. Estos elementos - reflexión a escala continental, búsqueda de soluciones conjuntas, factibilidad de la integración y circulación - se mantuvieron y se agudizaron en el siglo XX. Sin embargo, en la segunda mitad de este siglo se verificaron dos fenómenos que deben ponerse de relieve. Por una parte, se consagró un campo intelectual continental, culminación, ciertamente, del largo proceso al que ya me he referido. Se consagró porque las comunicaciones permitieron que los países de la región, su cultura y sus intelectuales se conocieran efectivamente. Surgieron revistas dirigidas al continente entero (y que se sumaron a algunas ya en circulación, como Sur, Repertorio Americano y Marcha); las editoriales publicaron a autores representativos del conjunto de países; se celebraron congresos con presencia heterogénea; se realizaron concursos que convocaron a todas las Américas... Puede decirse que nació así una opinión pública latinoamericana en la cual los intelectuales ocuparon un rol medular. Por otra parte, los pensadores latinoamericanos se integraron al mundo como nunca antes lo habían hecho. No sólo porque viajaron a lugares remotos - y en esto el desarrollo de los medios de transporte fue clave -, sino porque además el objeto de su pensamiento se liberó de límites y fronteras espaciales para pasar a ser un pensamiento global en todo el sentido de la palabra.

En la génesis de ambos fenómenos se hallan procesos políticos que determinaron el curso de la cultura, y si en la consagración 
del campo intelectual latinoamericano fue la revolución cubana un elemento fundacional, en la globalización lo fue la Guerra Fría. Por supuesto, no pueden separarse ni los fenómenos culturales ni los procesos políticos, más bien son caras de una misma moneda, caminos que se entrecruzan y se retroalimentan. Lo importante es destacar que desde 1945 en adelante, y sobre todo después de la Revolución Cubana (1959), el pensamiento y la acción de nuestros intelectuales tuvieron efectos sensibles en la política internacional, tanto en la latinoamericana como en la mundial. Pero hubo aun un elemento más que acentuaría esta conducta de los intelectuales: el surgimiento del Tercer Mundo, un nuevo referente ante el cual nuestros hombres y mujeres de letras reaccionaron a favor, en contra o críticamente, pero nunca con indiferencia. En suma, y a esto quiere apuntar este trabajo, el horizonte hacia el cual los intelectuales de América Latina dirigieron su mirada fue mucho más allá del Estadonación, y también más allá del continente: se ocuparon de Estados Unidos, de la Unión Soviética, del Tercer Mundo y de la situación mundial. Al mismo tiempo relacionaron cada uno de estos asuntos con América Latina: se cuestionaron, en definitiva, por el papel que el continente jugaba en procesos como la Guerra Fría o la constitución del Tercer Mundo.

Es un hecho poco discutible que históricamente los intelectuales de América Latina se han inclinado en su gran mayoría hacia la izquierda. Con la revolución cubana, con el desprecio tradicional a Estados Unidos - estimulado aun más por el escenario de la Guerra Fría, donde se le adjudicaba el papel de villano -, y con la irrupción del Tercer Mundo, dicha inclinación se exacerbó. Este trabajo, empero, analiza la trayectoria de dos intelectuales que, habiendo sido en su juventud militantes de izquierda, asumieron luego una posición de independencia y de crítica hacia el discurso y los movimientos de izquierda tradicionales (sin llegar a ser necesariamente de derecha, aunque sus críticos no dudaron en tildarlos asî). Sus nombres: Octavio Paz y Mario Vargas Llosa. 
El pensamiento político de Octavio Paz y Mario Vargas Llosa...

Situados en el escenario político global de la Guerra Fría con Revolución Cubana y Tercer Mundo de por medio -, tanto el mexicano como el peruano adoptaron una conducta y un pensamiento que los distinguió claramente de los otros sectores y redes en que se alinearon los intelectuales latinoamericanos. ${ }^{2}$ Ambos desplegaron una crítica constante hacia la Unión Soviética y hacia otros regímenes socialistas, y si bien ejercieron una vigilancia igualmente severa respecto al accionar de Estados Unidos, el criterio con que enjuiciaron a este país los diferenció nítidamente de la condena implacable que cundió entre la mayoría de los intelectuales de América Latina. Para Vargas Llosa y Octavio Paz, Estados Unidos no representaba el ogro causante de todos los males del continente ni tampoco el enemigo a vencer, más bien su prédica apuntó a lograr un entendimiento que en buena medida dependía, no obstante, de un cambio profundo en las políticas que Estados Unidos había dirigido históricamente hacia América Latina. También en lo que respecta al Tercer Mundo y al tercermundismo estos autores asumen un escepticismo temprano que se haría, en cualquier caso, bastante común entre los intelectuales de América Latina, aunque por distintos motivos. En rigor, el escepticismo de Paz apunta a la coherencia del concepto y a las contradicciones del tercermundismo, mientras que el de Vargas Llosa cuestiona los ineficaces proyectos de desarrollo en que el Tercer Mundo ha confiado. ${ }^{3}$

Claro que para llegar a estas posiciones ambos debieron recorrer una larga trayectoria.

Si Mario Vargas Llosa hubiese nacido un cuarto de siglo antes de seguro se habría encontrado con Octavio Paz en Valencia, en 1937, en el célebre II Congreso Internacional de Escritores (Antifascistas) por la Defensa de la Cultura, ${ }^{4}$ aquél que congregó a la flor y nata de la literatura mundial para solidarizar con el frente republicano en plena Guerra Civil española. Allí asistieron Pablo Neruda, Nicolás Guillén, Vicente Huidobro, Alejo Carpentier, Juan Marinello, César Vallejo, Carlos Pellicer, Raúl González Tuñón, 
Félix Pita Rodríguez y el joven poeta mexicano Octavio Paz. Vargas Llosa sólo tenía meses de vida para entonces. ${ }^{5}$

El tiempo se encargó de reducir esa distancia generacional entre el mexicano y el peruano - Paz nació el año 1914, Vargas el 36 -, haciéndoles recorrer trayectorias intelectuales en ocasiones asombrosamente parecidas. De partida, la presencia de Paz en Valencia ya nos habla de su temprana filiación izquierdista y aun marxista, si bien nunca llegó a militar en el PC mexicano. ${ }^{6}$ Vargas Llosa tuvo su iniciación política en un sector juvenil del Partido Comunista peruano, el grupo Cahuide. Ambos renegarán en la adultez de estos arranques revolucionarios que - intuyo - considerarían propios de veinteañeros. Vargas Llosa, incluso, casi fue presidente de su país representando a sectores de derecha. Con el tiempo se sucederán coincidencias biográficas e intelectuales, pese a lo cual no parece haber existido entre ellos una amistad o al menos una relación cercana; sí tuvieron contactos y colaboración, reconociendo además que los unía un modo de pensar semejante. ${ }^{7}$

\section{Guerra y Paz}

Octavio Paz pronto se desencantaría de la izquierda y del marxismo y muy especialmente de la utopía que imperaba durante sus años mozos: la Unión Soviética. Así, publica, en 1951, en la revista bonaerense Sur un informe sobre los campos de concentración soviéticos que le reporta el mérito de denunciar tempranamente los horrores que luego serían publicitados por la propia alta dirigencia soviética. No era fácil dar ese paso por lo impopular que resultaba condenar a la URSS al interior de la comunidad cultural de América Latina; Paz se atrevió y su atrevimiento acreditará en adelante su independencia intelectual. Será el propio Paz quien se esmere en mencionar el hecho cada vez que le fuera posible, subrayando que en México no quisieron aceptar su trabajo: "las 
publicaciones de izquierdas y aun las liberales estaban paralizadas por la guerra fría... No hay que darle armas al enemigo [se argumentaba]" (PAZ, 1981a, p. 239). Tuvo pues que recurrir a la argentina Sur - que no le debía nada a izquierdas ni derechas - para que apareciera el dossier con los documentos sobre los campos de concentración y el estudio introductorio de Paz. ${ }^{8}$

Insigne poeta, ensayista y dramaturgo, Paz en sus ensayos cubrió una gama abigarrada de temas que exploraron la estética, la literatura, la historia, la política, la biografía. Paz tuvo la suerte de recorrer el mundo gracias a su carrera diplomática. Trabaja en la embajada mexicana en París en dos periodos, entre 1946 y 1953 y entre 1960 y 1962. La verdadera riqueza de su periplo comienza en 1963, cuando se le designa embajador en la India. El subcontinente indio y los países de la región los recorrió interesándose vivamente por la cultura y la filosofía orientales. Su estadía tuvo un abrupto final a raíz de los hechos de la plaza de Tlatelolco en Ciudad de México, donde en 1968 fue reprimida violentamente una movilización estudiantil. Paz presenta la renuncia, plegándose a la ola de indignación levantada por intelectuales de México y del mundo.'

De vuelta en México, la trayectoria intelectual de Paz en los setenta será inseparable de la política, adquiriendo compromisos que contrastarán con la imagen que se había forjado en las décadas anteriores y que hablaba más bien de una distancia entre el hombre de letras y la actividad pública, que además se complementaba con cierto individualismo que lo hacía reticente a movilizarse colectivamente o a integrarse a redes. Es así como en 1971 funda junto con Luis Villoro y Carlos Fuentes el Comité Nacional de Auscultación y Consulta, que pronto se convertiría nada menos que en el Partido Mexicano de los Trabajadores. Por la personalidad de la que hemos hablado no sorprende que al poco tiempo Paz abandonara la agrupación. Más cómodo se sentía liderando un grupo de intelectuales mexicanos con el que compartía una misma sensibilidad y 
que tomó cuerpo en la revista Plural (1971-1976), dependiente del periódico Excélsior de Ciudad de México. Tras renunciar colectivamente a Plural nace Vuelta, publicación independiente de larga vida que no sólo se hará de un sólido prestigio, sino que también se constituirá en la voz que Paz, sus cercanos y colaboradores afines emitirán para participar en el debate nacional e internacional.

Es sobre todo en la década del setenta que el mexicano plasma un discurso acerca de la realidad y la situación mundial que destaca por el alto grado de elaboración con que analiza e interpreta la historia y el presente de las dos potencias antagónicas de la Guerra Fría, así como la naturaleza del Tercer Mundo. Ciertamente es un análisis que se venía gestando con anterioridad y que tiene antecedentes tan remotos como aquel informe de 1951. Más tarde, en los ochenta, se visualiza en Paz una actitud algo pesimista basada que no descartaba una solución violenta y por ende catastrófica de las tensiones globales.

\section{Estados Unidos versus Unión Soviética}

Octavio Paz fue uno de los escritores latinoamericanos que con mayor rigor se refirió al conflicto mundial, a lo cual agregó la particularidad de explicitar sus reflexiones sin temor de ser atacado como efectivamente sucedió - por sus pares. Parte de la siguiente premisa: "La civilización industrial, en sus dos vertientes: la capitalista y la comunista, ha logrado la unanimidad en la reprobación" (PAZ, 1967, p. 177). Sí hacía la salvedad de que un futuro soviético sería nefasto para la humanidad. Así, Estados Unidos sería el mal menor.

Todo había empezado en Sur, en ese artículo que no es sólo una denuncia, sino también la primera elaboración de una larga cadena de análisis sobre el mundo soviético. El texto va más allá de la mera descripción de los campos y ensaya una explicación profunda de su existencia. Quienes ingresaban al sistema carcelario, 
ya sea por una sentencia judicial o por decisión del Comisariato de Asuntos Interiores, que además administraba los recintos, pasaban directamente a engrosar las fuerzas productivas de la URSS en número apreciable: sumaban entre 6 y 8 millones según algunos o más de 20 al decir de otros. Dedicados al trabajo correctivo los detenidos constituían una pieza clave en la industrialización acelerada a la cual estaba consagrada la economía soviética. Para Paz los internos conforman la base de la pirámide social, que por cierto encabeza la burocracia, reeditando en la práctica un régimen esclavista. Concluye Paz: "Los campos son algo más que una aberración moral, algo más que el fruto de una necesidad política: son una función económica" (PAZ, 1981a, p. 237).

Esta postura lo llevó a enfrentarse a muchos intelectuales de izquierda, los cuales, frente al problema de los campos, pensaban que ese "sistema de opresión y explotación no es un rasgo inherente y esencial del 'socialismo' totalitario sino apenas un accidente que no afecta a su naturaleza profunda" (PAZ, 1981, p. 13). Es contra los enceguecidos intelectuales que Paz se rebela:

cierran los ojos ante la realidad de la burocracia soviética, su policía omnipresente y omnipotente, sus campos de concentración y la política imperialista de Moscú, para ver con la mente la imagen de una patria socialista, libre, pacífica y feliz (PAZ, 1981f, p. 61).

Todavía en 1991, cuando ya la Guerra Fría ha terminado y la Unión Soviética desaparecido, persevera en su acusación, esperando quizá un reconocimiento o un acto de contrición:

Si la conversión a la democracia de nuestros intelectuales de izquierda es realmente sincera, tiene que ir acompañada por una confesión: fueron cóm-plices - acepto que, en la mayoría de los casos, de manera involuntaria y de buena fe - de un crimen inmenso (MARRAS, 1992, p. 453). ${ }^{10}$ 
Las revelaciones acerca de los campos de concentración son la manifestación visible de un sistema corroído y corrompido fundamentalmente por la acción de un Estado secuestrado por la elite dirigente:

En la Unión Soviética el Estado es el propietario de las cosas y de los hombres, quiero decir: es el dueño de los medios de produc-ción, de los productos y de los productores. A su vez, el Estado es la propiedad del Partido Comunista y el Partido es la propiedad del Comité Central (PAZ, 1981h, p. 89).

La dictadura del proletariado o la sociedad socialista igualitaria que prometían el marxismo y la revolución bolchevique ha sido reemplazada por el dominio de una burocracia fosilizada que sólo es indicio de la real naturaleza de la URSS: una sociedad de castas en la que el supuesto beneficiario de la revolución, el proletariado, ha sido más bien perjudicado:

En la Unión Soviética los sindicatos todavía tienen que luchar
por su independencia y todavía los obreros deben conquistar
la libertad de asociación y de reunión. En Rusia la clase obrera
está más explotada y oprimida que en los países capitalistas
(PAZ, 1981c, p. 312).

De lo que llama "seudo socialismos" salen "infiernos" como el soviético. Aunque siempre se declaró socialista, Paz entendía por socialismo algo por completo diferente a lo ensayado en la URSS, donde se ha cometido una perversión de la doctrina. Su socialismo quiere decir igualdad, democracia profundizada, regulación del capital privado. Quizás es más gráfico cuando dice lo que no es: el socialismo es la sociedad ideal, pero no el medio para alcanzar esa sociedad, porque es indispensable alcanzar primero el desarrollo económico, y en esa tarea el capitalismo es el mejor medio para lograrlo, pese a todas las implicancias inhumanas que comporta. En suma, "el verdadero socialismo es una consecuencia de la abundancia y no un método para crearla” (PAZ, 1967, p. 179). 


\section{El pensamiento político de Octavio Paz y Mario Vargas Llosa...}

Con todo, la verdadera esencia de la Unión Soviética radica en una histórica vocación imperialista y guerrera que la empuja a políticas expansionistas y a la constitución de un estado burocrático y militarizado que guarda fuertes reminiscencias del zarismo. A diferencia del imperialismo estadounidense, que prefiere llamar hegemonía ("influencia predominante de un Estado sobre otro"), pues busca aliarse con otras naciones - poniendo y sacando gobernantes, estableciendo socios comerciales, firmando tratados de colaboración -, el ruso, orientado por el deber de convertir al mundo, se consuma sólo con un dominio pleno que excluye otros sistemas de gobiernos e ideologías: "La Unión Soviética ha vuelto a la antigua concepción del imperialismo, que identificaba la dominación con el poder directo sobre los territorios, los gobiernos y las poblaciones" (PAZ, 1967, p. 68). Que la URSS sea la potencia más agresiva y expansionista de la segunda mitad del siglo no se explica sólo por su noble fin socialista sino que obedece también a la resolución de conflictos internos. La sociedad soviética está cruzada por graves contradicciones que son resultado de su organización en castas, pues mientras la burocracia defiende el inmovilismo la población sufre los efectos de la industrialización y pugna por un cambio social. Al mismo tiempo las poblaciones de las naciones sometidas a Moscú no parecen dispuestas a perpetuar su precaria situación y luchan en pos de su identidad. Estas dos tensiones son sofocadas por el poder a través de la represión en el interior y la expansión en el exterior. La necesidad de preservar una sociedad que vive entre la petrificación y el estallido exacerba la beligerancia con que la URSS amenaza al mundo entero:

El Estado militar ruso, como todos los Estados militares, sólo sabe - sólo puede - hacer bien una cosa: la guerra. La diferencia con el pasado es que los antiguos Estados Militares no disponían de armas nucleares (PAZ, 1967, p. 69).

Estados Unidos, aun cuando es mejor evaluado que su rival, resulta igualmente reprobado. También entraña cánceres que lo 
harán tambalear, pero en ningún caso desaparecer, destino que sí le augura a los soviéticos. El dilema que los norteamericanos deben sortear atañe nada menos que a su naturaleza última: democracia o imperio. La democracia, que corresponde al orden interior, es el fundamento histórico de la unión, y al escudriñar en su origen se obtienen las claves que permiten entender las tribulaciones de su acontecer político actual. Es que para Paz la democracia se enraíza en principios morales heredados del puritanismo profesado por los fundadores del país, por lo cual el comportamiento y la toma de decisiones de la clase dirigente está siempre transida de condicionantes éticos que lo menos que hacen es generar contradicciones. Como ejemplo Paz sostiene: "La presencia de la ética religiosa protestante transforma un incidente como el de Watergate en un conflicto que toca los fundamentos mismos de la democracia norteamericana" (PAZ, 1981f, p. 59). Sentimientos de culpabilidad son inherentes a los norteamericanos y en ello incide una suerte de fascinación por la crisis y la decadencia que representa un grave riesgo de paralización pero que también proporciona el principio de autocrítica - y hasta autoflagelación - que es en definitiva el camino que conduce a la reforma y a la salvación.

No hay que ir muy lejos para reconocer en distintos sucesos políticos y sociales ese espíritu de autocrítica que caracterizaría a los norteamericanos. En los sesenta el movimiento negro por los derechos civiles y la movilización estudiantil pusieron en tela de juicio el sistema. Pero fue con la Guerra de Vietnam que emergió una transversal conciencia culposa - en consonancia con la condena internacional - que cuestionó rudamente no sólo la capacidad de los gobernantes y de los partidos que conducían la república sino también su honestidad y moralidad. En ese sentido Paz asevera que la derrota en Vietnam fue menos militar que moral y política, pues se trató de una intervención reprobable y cruel que obligó a una salida vergonzosa.

Las prácticas imperialistas ponen bajo peligro la democracia interior, pero a la vez responden a necesidades de política interna: 
"La contradicción de los Estados Unidos - la que les dio la vida y puede causar su muerte - se resume en una pareja de frases: al mismo tiempo son una democracia plutocrática y una república imperial" (PAZ, 1981f, p. 67). En Estados Unidos la democracia ha perdido pureza y ha sido corrompida por el dinero dándose origen a una democracia plutocrática. La plutocracia provoca y acentúa la desigualdad social conculcando las libertades públicas y los derechos individuales; al mismo tiempo, sin embargo, la plutocracia es generadora de riquezas que mitigan la desigualdad, mas el costo es el traspaso de esa desigualdad "escandalosa" al concierto internacional, lacerando a los países subdesarrollados. Luego, para rescatar a la democracia de las manos del dinero sería necesario renunciar al imperio, pero ¿cómo hacerlo sin ser inmediatamente destruido por el expansionismo ilimitado de los soviéticos?, se pregunta.

Entretanto, EE.UU. ha comenzado una lenta declinación "alcanzó ya su mediodía"- que muestra como síntoma la disminución de su poderío militar y el rezago armamentista frente a la URSS, desventaja que por el bien de todos debe aminorar, pero duda Paz de que exista la voluntad y calidad política como para lograrlo. Y es que el ejercicio del poder en los últimos años ha evidenciado la inoperancia y corrupción de políticos cínicos, miopes, abusivos con los débiles y mansos con los poderosos, que para peor vuelcan los sucios métodos usados por el imperio contra la propia nación, como lo prueba el espionaje de Watergate: "las armas que el Estado imperial esgrime en contra de sus enemigos del exterior fatalmente se convierten en instrumentos que la burocracia política usa contra los ciudadanos independientes" (PAZ, 1981f, p. 68).

Motivo de indignación es para el poeta la intervención norteamericana que desestabilizó al presidente Allende en Chile y que culminó con el golpe de Estado; claro que hace extensiva la censura a Moscú: "La paz que construyen las superpotencias se edifica sobre la humillación de los pueblos, el sacrificio de los disidentes y los despojos de las democracias destruidas: Grecia, Checoslovaquia, 
Uruguay, Chile” (PAZ, 1981d, p. 271). Crea una analogía entre los tanques rusos y los generales chilenos entrenados por el Pentágono, y aun es más gráfico y agresivo cuando expresa: "mientras Nixon se lava las manos sucias de Watergate en el lavamanos ensangrentado que le tiende Kissinger, Brejnev inaugura nuevos hospitales psiquiátricos para disidentes incurables" (PAZ, 1981d, p. 271).

Bien entrado en los ochenta el orden mundial es visto por $\mathrm{Paz}$ como un frágil equilibrio que en cualquier momento puede quebrarse y traer consecuencias lamentables. La paridad nuclear y el mutuo temor son los garantes de la paz y los causantes de que tanto en el Este como en el Oeste se presencie una inmovilidad que fácilmente puede revertirse y derivar en aniquilamiento, una amenaza que el belicoso siglo XX atestigua confirmando su latencia: "El terror nos ha preservado del gran desastre, pero no nos hemos escapado de la guerra ni un solo día desde 1945" (PAZ, 1985, p. 33).

Una vez más el poeta se verá envuelto en enfrentamientos con otros intelectuales, aunque esta vez la polémica girará en torno a la situación de Nicaragua. En el Festival Horizontes de Berlín en 1984 se despacha unas declaraciones contrarias al régimen de Managua provocando una ola de quejas de parte de escritores europeos y latinoamericanos presentes en el evento, como Günther Grass, Juan Rulfo, Juan Bosch y Antonio Skármeta. El descontento trasciende las fronteras y desata ecos en México, donde grupos de manifestantes profieren a Paz una ácida consigna: "Reagan, rapaz, tu amigo es Octavio Paz", ${ }^{11}$ aludiendo a la complicidad con que el poeta - acusado de agente de la CIA - allanaba el camino para una invasión norteamericana a Nicaragua. En uno de los actos se quemó un monigote que representaba la figura del futuro Premio Nobel (PONIATOWSKA, 1998, p. 181-182). Lejos de medrar en sus apreciaciones las reiterará en Bonn al agradecer el Premio de la Paz de los Editores y Libreros Alemanes 1984. Allí, alarmado ante lo que sospecha puede derivar en una nueva Cuba, es decir en una "dictadura burocrático-militar", rechaza la ayuda militar y técnica que Nicaragua 
El pensamiento político de Octavio Paz y Mario Vargas Llosa...

ha recibido de la URSS y sus aliados, al tiempo que condena el apoyo que Estados Unidos dispensa a grupos armados opositores como los contras.

\section{Escéptico del Tercer Mundo}

La noción de Tercer Mundo fue desde su inicio muy discutida $\mathrm{y}$, como suele suceder en estos casos, muchos se resistieron a su uso; se le restó validez como categoría, se le calificó de imprecisa y poco rigurosa; pero pese a todo se usó y se siguió usando, lo cual ya justifica su existencia. Paz arremete contra el término por la excesiva generalización que supone; su impresión es que lo integran, en teoría, países con tal heterogeneidad que englobarlos a todos bajo un mismo concepto es un despropósito. ¿Qué enlaza a Zaire, Argentina o Birmania?, se pregunta, para luego falsear la prescripción que estipula que son tercermundistas las sociedades no-industrializadas y dependientes, oponiendo los casos de Checoslovaquia, que juzga industrializada pero dependiente, y China, independiente pero no del todo industrializada. En el plano local desaprueba clasificar a México dentro de un grupo de naciones que en su gran mayoría no pertenece a la civilización occidental (PAZ, 1981b, p. 126-127). Y es que justamente el mayor y más efectivo núcleo aglutinador de los países tercermundistas es la negación de la occidentalidad:

Colección abigarrada de pueblos en andrajos y civilizaciones en añicos, la heterogeneidad del 'tercer mundo' se vuelve unidad frente a Occidente: es el otro por definición, su caricatura y su conciencia, la otra cara de sus inventos, su justicia, su caridad, su culto a la persona y sus institutos de seguridad social (PAZ, 1967, p. 213).

Oscilante entre querer y no querer ser como las sociedades desarrolladas, lo que mejor define al Tercer Mundo es, por ahora, su voluntad de ser (PAZ, 1967, p. 214). 
No parece en todo caso privar de historicidad al Tercer Mundo, lo cual es ya una forma de emplear y legitimar el término. En los sesenta y en medio del fragor revolucionario de la hora, Paz se hace cargo del acontecer político mundial catalogando como "revueltas" - y no revolución - los movimientos de liberación de los países del Tercer Mundo.

El Mayo del 68 francés le causa un tan hondo entusiasmo que le hace prefigurar el advenimiento de la primera revolución socialista en un país desarrollado, lo que para Paz sería la primera revolución auténtica. Cree firmemente que la revolución ha empezado en Francia y en Europa, pero es tan grande su ilusión como su temor, pues de fracasar el movimiento se asistiría al fin de Europa como entidad independiente y al inicio de la total hegemonía ya no sólo soviética sobre la mitad oriental del continente, sino también de la norteamericana sobre la otra mitad, posibilidad que juzga simplemente aterradora (PAZ y ORFILA, 2005, p. 165). La mentada revolución socialista no prospera, lo que obliga al poeta a clasificar los estallidos sociales observables en la época en tres categorías: revuelta, rebelión y revolución. Expresa que en el mundo desarrollado la revolución no es posible mientras los jóvenes sólo postulen cambios puntuales que no comprometan las bases del sistema. Lo que se presencia entonces en Europa y especialmente en Estados Unidos es una simple rebelión.

La revolución tampoco asoma en el Tercer Mundo porque no cumple con una de las exigencias de toda revolución: la pretensión de universalidad. Afirma que los proyectos actuales tienen un alcance regional - el régimen de Nasser en Egipto, el socialismo argelino, la experiencia cubana. En definitiva, en el mundo subdesarrollado emergen "revueltas locales" que, al igual que las rebeliones del primer mundo, no son merecedoras del sello revolucionario:

La revuelta del 'tercer mundo' es un movimiento pluralista que no se propone la creación de una sociedad universal. Las formas políticas y sociales que adopta, del socialismo 
estatal a la economía privada, no son fines en sí sino medios para acelerar su evolución histórica y acceder a la modernidad (...) Carece de una teoría general revolucionaria y de un programa (...) En una palabra: es una revuelta mundial pero no es ecuménica (PAZ, 1967, p. 213).

La sublevación del Tercer Mundo aún busca su significado final, lo cual es natural dado su carácter eminentemente popular y espontáneo; mas su fortaleza radica en que involucra a la mayoría de la humanidad y en que comporta una reivindicación de las peculiaridades culturales, vale decir religiosas, artísticas y filosóficas, en cuya originalidad y heterogeneidad fundan su derecho a la universalidad. Es además una lucha justa y legítima que puede prosperar, es más, para América Latina tal vez sea la última opción de acceder a la historia.

El resguardo de la identidad de los pueblos del Tercer Mundo es quizá el desafío más delicado ya que el inexorable ingreso a la modernidad impacta a las culturas tradicionales y germina en ellas una doble personalidad o inautenticidad. Es preciso entonces enfrentarse a la realidad y hacer una crítica despiadada de sí mismos, de lo contrario la escisión psíquica, la enajenación y la muerte del alma desvirtuarán la revuelta y la dejarán a merced de cesarismos delirantes y de burocracias cínicas (PAZ, 1967, p. 217-218).

Alrededor de 1980 Paz lamentará el destino de los pueblos que en vez de alcanzar una verdadera liberación son golpeados por tiranías despiadadas - Vietnam, Indonesia, Angola, Camboya, Libia, Irak y los países de América Latina - que proliferan junto a guerras internas y externas, intervenciones de las potencias, matanzas, etc. Por otra parte expresa su decepción ante la Organización de Países No Alineados, nacida para resistir, mediante una actitud crítica y moral, los abusos que los Estados más poderosos e incluso la ONU propinaban a los países pequeños. En los hechos los países miembros se han dejado contaminar por ideologías y han renunciado al papel de ejemplos morales que en un principio 
habían esbozado. Han menguado su credibilidad desde el momento en que aislaron la animadversión hacia Occidente como la única bandera con poder de convocatoria. Es comprensible este sentimiento de acuerdo a la calidad de ex-colonias de sus asociados, aunque el que concentra mayor inquina, Estados Unidos, no es un colonizador clásico, pero se ha ganado el desprecio por ser aliado y cabeza de los países efectivamente colonialistas. Tal combinación ha sido explotada por el enemigo, los soviéticos, quienes han procurado que la Organización sirva como foro de protesta contra Europa y Estados Unidos, o bien como una mera oficina propagandística, como teme Octavio Paz. El poeta desearía que la Organización recuperara su independencia, pero lo ve difícil puesto que la aceptación de Estados dudosamente no-alineados - piensa en Cuba - fue un error difícil de enmendar (PAZ, 1990, p. 85-86).

\section{Mario Vargas Llosa y la guerra del fin del mundo}

Contra viento y marea. Así titula Vargas Llosa un volumen que recopila ensayos, entrevistas, cartas y artículos escritos entre 1962 y 1982; pero así podría titularse también su batalla personal contra un sector de la inteligencia latinoamericana que no toleró sus posturas críticas contra regímenes y grupos de izquierda y que lo identificó mecánicamente con la derecha. Al revisar el sendero intelectual de Vargas Llosa queda claro que hacerse de enemigos no le resultó difícil, y que tampoco se desvivía por caer bien. Ante los ataques por su supuesta obsecuencia con el capitalismo, Estados Unidos o las derechas, siempre rebatió ostentando su férrea oposición a las dictaduras, de cualquier signo político. ${ }^{12}$

Decir que los latinoamericanos debemos mirar a Estados Unidos como un espejo a imitar y que para bien o para mal estamos mucho más cerca de ellos que de sus enemigos es un atrevimiento que basta para explicar la animadversión que se ganó en el medio. En un remoto pasado había quedado ese joven estalinista que 
enjuiciaba a los Estados Unidos sin conmiseración culpándolos, como él lo recuerda, de los males que desahuciaban a los países de América Latina. Comprendía en ese entonces que los padecimientos de los países del continente arrancaban de la explotación de las compañías internacionales y del contubernio entre éstas y las dictaduras militares que eran a su vez amparadas por Estados Unidos. Esa fue la explicación de los problemas de América Latina que predominó durante la Guerra Fría, y de ella Vargas Llosa abjurará rotundamente (MICHNIK, 1997).

Fue una vez que comprendió el significado del capitalismo en toda su dimensión, es decir, con sus virtudes y defectos, que su pensamiento - confiesa - cambió de dirección. El capitalismo es el único sistema que posibilita la acumulación de bienes materiales, elemento indispensable para el crecimiento económico. Sin embargo, la adhesión al capitalismo no significa inmediatamente una predilección por Estados Unidos ni mucho menos, más bien su esfuerzo se dirige a sentar la supremacía de un modelo económico por sobre otro, en este caso, del capitalismo por sobre el socialismo, y a canonizar la democracia como el único régimen político que garantiza una implementación adecuada de dicho capitalismo. Para Vargas Llosa lo económico y lo político se determinan mutuamente, de hecho - sostiene - en los países desarrollados de economía de mercado funciona mejor la democracia, la libertad y la fiscalización del poder. El problema es que en esos mismos países se incuban desigualdades económicas abusivas, tanto al interior - por ejemplo, la distinción entre los trabajadores intelectuales y manuales -, como al exterior - la explotación y el saqueo de los países pobres (VARGAS, 1985d, p. 316).

A Estados Unidos los dardos de Vargas Llosa nunca dejarán de llegar, por más que le reconozca méritos que pocos intelectuales latinoamericanos suscribirían. Por cierto, no arremete contra el pueblo norteamericano, al contrario, lo valora por su respeto a la libertad, la tolerancia, la equidad y la representatividad, y asegura 
que es ajeno por completo a las decisiones de su gobierno. Es hacia la política exterior de Estados Unidos que el peruano apunta sus reparos. La situación de Nicaragua hacia finales de los ochenta y el modo en que ha sido enfrentada por Estados Unidos motivan al peruano para revisar la política desplegada históricamente por este país en América Latina, concluyendo que en realidad nunca ha existido esa política, lo que explica su andar errático. Sólo rescata el frustrado intento de Kennedy, la Alianza para el Progreso - decir esto es un anatema para la comunidad intelectual de América Latina -, y la propone como inspiración para la futura implantación de políticas "sensatas y positivas". La ineptitud mostrada en Nicaragua, por tanto, no es más que la prolongación de la inoperancia histórica que ha mostrado Estados Unidos en la región, y que en el caso nicaragüense es aun más palpable si se investiga el origen del proceso, a saber, la dictadura de Somoza, a quien EE.UU. socorrió militar, financiera y diplomáticamente (SETTI, 1989, p. 173). Ha preferido "lidiar con el gorila servil" antes que impulsar una Nicaragua soberana y democrática, y ahora, con la revolución en marcha, se ha vuelto a equivocar, primero, ayudándole, pero mal; y luego, sustentando la resistencia de los "contras". ${ }^{13}$

Si Estados Unidos promoviera en América Latina la democracia que practica internamente, y si respaldara los gobiernos democráticos de la región hostilizando al mismo tiempo a las dictaduras de derecha y de izquierda, sin duda tendríamos que agradecerle por fin una política beneficiosa hacia Latinoamérica:

Pero al mismo tiempo Estados Unidos es una sociedad de la que estamos más cerca nosotros, si es que queremos ser países democráticos. Eso es muy importante tenerlo en cuenta, para América Latina, Estados Unidos no puede ser nunca el enemigo principal, a no ser que nosotros no queramos la democracia para América Latina, sino sociedades totalitarias (SETTI, 1989, p. 173). 
El pensamiento político de Octavio Paz y Mario Vargas Llosa...

A fin de cuentas, parece asumir con pragmatismo Vargas Llosa, "estamos más cerca del sistema norteamericano que del sistema de los adversarios de Estados Unidos” (SETTI, 1989, p. 174).

¿Y cuál es ese sistema y esos adversarios? El socialismo y los soviéticos, desde luego. A su juventud comunista, a su estalinismo, Vargas Llosa sumará respeto y simpatía por la Unión Soviética hasta bien entrados los sesenta. Será entre 1966 y 1969 que asistirá a una serie de eventos que lo convirtieron irreversiblemente en detractor de la URSS. Es interesante que, así como fue el realismo socialista el que lo alejó del comunismo, será un conflicto literario el que abrirá la brecha del desencanto de Vargas Llosa. Ante el juicio contra Siniavski y Daniel en la Unión Soviética el peruano alzó fuerte la voz:

Los escritores que creemos en el socialismo y que nos consideramos amigos de la URSS debemos ser los primeros en protestar, con las palabras más enérgicas, por el enjuiciamiento y la condena de Andrei Siniavski y Yuli Daniel, los primeros en decir sin rodeos nuestro estupor y nuestra cólera. Este acto injusto, cruel e inútil no favorece en nada al socialismo y sí lo perjudica, en vez de prestigiar a la URSS la desprestigia (VARGAS, 1985a, p. 86). ${ }^{14}$

Se observa que hay una valoración positiva de la URSS y que se trata de una crítica constructiva y en ningún caso definitiva:

¡La estable, la poderosa Unión Soviética, la patria de los cohetes que viajan a la luna, se vería en peligro por dos volúmenes de relatos fantásticos (...) y por un ensayo hostil al realismo socialista? Ciertamente no (VARGAS, 1985a, p. 86).

Cree que la formulación de los delitos, el proceso y la sentencia son injustificables, y no lo serían incluso si existieran delitos graves, como un ataque frontal a la URSS, a su gobierno, sus leyes y principios, o sea, al fundamento mismo del socialismo. 
Entiende el hecho como un escarmiento preventivo destinado a frenar o moderar la tendencia crítica y anticonformista que ciertos escritores estarían cultivando (VARGAS, 1985a, p. 86).

Un nuevo foco de polémica, y otra vez literario, se encenderá al año siguiente con la carta que Alexandr Solzhenitsin envió al Congreso de Escritores Soviéticos cuestionando algunos aspectos de la política cultural del Kremlin, en especial la censura:

[Son cargos] que no pueden dejar de alarmar y apenar a ningún escritor, y sobre todo a aquellos que estamos convencidos de los gigantescos beneficios que trajo la revolución al pueblo ruso y ambicionamos una solución de carácter socialista para los problemas de nuestros propios países (VARGAS, 1985b, p. 126). ${ }^{15}$

Confía en que el sistema soviético remediará desde adentro esa sombra que se cierne sobre la cultura y que se llama censura; así,

podrá también exhibir ante el mundo, en el campo de la literatura, realizaciones tan magníficas como las que ha logrado en los dominios de la ciencia y la justicia social. Porque es mentira que el socialismo este reñido con la libertad de creación (VARGAS, 1985b, p. 130).

1968 fue el año decisivo para Vargas Llosa. La ola de condenas que supuso para la Unión Soviética el ingreso de sus tanques en Praga envolvió también al peruano, que entonces hizo pública una defección que sería no sólo conservada sino acentuada con el paso de los años. ${ }^{16}$ Sin embargo, más importante que lo de Praga fue el viaje personal que poco antes había realizado a Moscú. Era su primera visita y las conclusiones fueron categóricas: "Fue la decepción más grande que jamás haya vivido. Nunca me hubiera imaginado que eso pudiera ser el socialismo" (MICHNIK, 1997).$^{17}$ Señala - años después - que le impactó ver cómo los dirigentes 
detentaban beneficios inimaginables para el resto de la sociedad, que iban desde la posesión de un auto hasta la posibilidad de viajar al extranjero, pasando por el derecho a la movilidad al interior del país: "Eso colocaba a una persona tan por encima del común de los mortales que la convertía en una especie de semidiós" (SETTI, 1989, p. 152). ${ }^{18}$

Según sus palabras se convirtió en un crítico vehemente de la URSS. Debutó propinando un golpe bajo a quienes siempre condenaron el imperialismo norteamericano: reconocer un imperialismo parecido o peor en la Unión Soviética, hasta entonces ejemplo de convivencia entre las naciones que la conformaban:

Agresión [a Checoslovaquia] de carácter imperial que constituye una deshonra para la patria de Lenin, una estupidez política de dimensiones vertiginosas y un daño irreparable para la causa del socialismo en el mundo. Su antecedente más obvio no es tanto Hungría como República Dominicana (...) Es tan condenable como el envío de infantes de marina norteamericanos a Santo Domingo para aplastar por la violencia un levantamiento popular contra una dictadura militar y un sistema social injusto (VARGAS, 1985c, p. 160). ${ }^{19}$

Aunque menos sangrienta que la de Santo Domingo, es igualmente inmoral, pues ambas constituyen agresiones abusivas en contra de países pequeños. Las potencias se justifican de igual modo: para unos está amenazada la democracia y para los otros el socialismo; además, sus acciones siempre son supuestamente solicitadas por las víctimas, es en nombre de ellas que actúan.

Mientras el ídolo soviético caía, el ídolo cubano aún sobrevivía. Pero con la postura de Fidel Castro ante los hechos, a Vargas Llosa le empezó a tambalear su fe en el socialismo cubano y en su capacidad de democratizarse internamente. Aunque se resistía a homologar el régimen cubano con el soviético, el precedente de Praga y la declaración de Castro le hicieron temer que el socialismo cubano sería sometido tarde o temprano a las directrices de Moscú: 
¿no comprende [Castro] que si reconoce a la URSS el derecho a decidir el tipo de socialismo que conviene a los demás países y el de imponerles su elección por la fuerza, lo ocurrido en Praga hoy podría ocurrir mañana en La Habana? (VARGAS, 1985c, p. 163). ${ }^{20}$

No sólo Cuba resultaba eventualmente afectada por la crisis checoslovaca, era todo el Tercer Mundo el que se veía amenazado por las potencias. Afirmaba que lo que está en juego

no es la pugna entre capitalismo y comunismo, sino el destino de los países que conforman el Tercer Mundo. Una terrible perspectiva parece ennegrecer su horizonte histórico: vivir perpetuamente a merced de los grandes colosos, mantenerse enajenados entre dos formas de servidumbre colonial (VARGAS, 1985c, p. 160).

El panorama algo tremendista que dibuja Vargas Llosa parece denotar el fuerte impacto que le significó ver derrumbarse una de sus convicciones más caras, y no era para menos, porque, con una Cuba cada vez menos esperanzadora, no se alzaban en el horizonte modelos a imitar. Con los años, Estados Unidos llegará parcialmente a ocupar ese lugar.

Vargas Llosa en los setenta aguzará y diversificará su crítica en todas direcciones: la URSS, Estados Unidos, el resto de los países desarrollados, Cuba. Se preocupa por el futuro de un Tercer Mundo que está a merced de las potencias y empantanado económicamente por obra de los países ricos, cuya culpa consiste en usufructuar del subdesarrollo mediante términos de intercambio indignos, y en escamotear la ayuda necesaria, o bien brindándola a cambio de imposiciones políticas y militares. La responsabilidad de que en el Tercer Mundo abunde la barbarie, la desnutrición, el hambre, la mortalidad infantil, la ignorancia y la miseria - que hacen de la existencia una muerte lenta -, también involucra a las castas nativas - 
entregadas al lujo y al exceso -, a los ejércitos de opereta y a los mismos intelectuales, igualmente subdesarrollados.

En la década del ochenta la Guerra Fría tuvo su desenlace, un desenlace pacífico que se decidió por el agotamiento de uno de los rivales. Pero hacia 1982 ni se sospechaba de esto. Ese año en Polonia el movimiento Solidaridad alcanzó un crecimiento importante que impresionó positivamente a intelectuales como Octavio Paz y Vargas Llosa. La represión con que finalmente los soviéticos sofocaron la agitación provocó la angustia del peruano, pues los países occidentales no se atrevieron a tomar medidas concretas contra los gobiernos polaco y soviético con el fin de no alterar las relaciones económicas y seguir ganando dólares. Ello revela que Occidente no tiene la convicción moral suficiente para responder a la prepotencia rusa, lo cual le parece trágico "porque lo que se deduce de ahí es que el imperialismo soviético, enfrentado a esa actitud, ganaría pacíficamente la guerra”. La esperanza recae entonces en los pueblos subyugados por el socialismo y no en los países occidentales:

Por fortuna, los pueblos como el polaco no están dispuestos a aceptar ese estado de cosas. [Paradójicamente,] si alguien puede salvarnos del totalitarismo son los pueblos sometidos a la ideología socialista y no los países supuestamente democráticos (TORRES, 1986, p. 293-294).

Algo de eso finalmente ocurrió, para alivio del autor de $L a$ guerra del fin del mundo.

\section{Conclusiones}

Cuando piensan en la Guerra Fría, en Estados Unidos, en la Unión Soviética, en el Tercer Mundo, Octavio Paz y Mario Vargas Llosa nunca dejan de estar pendientes de América Latina. Hasta 
podría decirse que, si piensan esos temas, es porque lo que realmente les preocupa es América Latina. Si analizan las ventajas y desventajas del capitalismo y del socialismo es porque aspiran a aplicar en el continente la receta que por fin saque a Latinoamérica de su atraso. Si les preocupa la política exterior de Estados Unidos en el mundo es porque se sienten amenazados, pero también esperanzados en que, desde el norte, provenga algún día la ayuda tantas veces mezquinada. Si analizan a la Unión Soviética es porque temen su fuerza expansionista, ésa que ya ha arrastrado a Cuba por el falso camino del socialismo universal. Lo de Cuba provoca la alerta sobre Nicaragua, que bien puede convertirse en nueva presa de Moscú o de Washington. Si cuestionan los caminos por los que transita el Tercer Mundo es porque están atentos a los beneficios o perjuicios que pueden acarrear para el continente. En la segunda mitad del siglo XX, es inconcebible, según lo que Paz y Vargas Llosa muestran, pensar bajo un horizonte acotado a lo nacional o a lo continental; sin embargo, por muy global que fuese ese pensamiento, la consideración de lo latinoamericano está siempre presente en la reflexión.

A lo largo de lo expuesto han aflorado aquellas ideas que caracterizaron a Paz y a Vargas Llosa y que los distinguieron de lo que pensaba la mayoría del campo intelectual latinoamericano. Referirse a Estados Unidos con un ánimo constructivo distaba mucho de la actitud histórica y tradicional de la intelectualidad continental, por mucho que ese ánimo fuera acompañado de una seria condena a dicho país en diversos sentidos. Es altamente elocuente que Paz prescindiera de la categoría "imperio" para definir a Estados Unidos, encarnación plena, según gran parte del campo cultural, del imperialismo rapaz que ha asolado al mundo y especialmente a América Latina. Qué decir del anhelo de Vargas Llosa de acercarse a Estados Unidos, convertido en mixtura de espejo y de tabla de salvación para Latinoamérica. La disposición crítica hacia la Unión Soviética, precoz en el caso de Paz, no tanto en Vargas Llosa, 
no era común. Pocos meses antes de morir, Julio Cortázar habría escrito:

hay dos personas, entre los escritores latinoamericanos, que son Octavio Paz y Vargas Llosa, que hacen críticas a la Unión Soviética por los problemas de los derechos humanos, que no podemos descartarlas, así tan de plano; tenemos que preguntarnos si no tienen algún elemento de razón. ${ }^{21}$

Este trabajo deja pendiente una discusión acerca del componente liberal que da vida al pensamiento de Paz y Vargas Llosa. Éste último se ha declarado explícitamente liberal, y Paz también recogía del liberalismo principios caros a su sistema de pensamiento. El modo en que dicha vertiente ideológica se filtra en el discurso de ambos autores sobre los temas aquí tratados es, por tanto, la pregunta a resolver en un próximo paso.

\section{The political thought of Octavio Paz and Mario Vargas Llosa: Latin America in the polarized world}

Abstract: This article studies the thought of the Latin American writers Octavio Paz and Mario Vargas Llosa in the light of the more significant political processes in the second half of the $20^{\text {th }}$ century: the Cold War, the struggle of the Third World and, in the continental aspect, the revolutionary cycle, with its successes and failures. This perspective is analyzed in order to prove, first, the globalization of the Latin American intellectuals, and second, the singularities of the ideas of both writers, in comparison with the ideas of the intellectual field in general.

Keywords: Octavio Paz. Mario Vargas Llosa. Latin American Intellectuals. Latin American thought. Cold War.

\section{Notas}

${ }^{1}$ Pese a que los intelectuales brasileños provienen de una cultura diferente a la legada por España, es interesante constatar que se han integrado a la comunidad intelectual hispanoamericana en un nivel mayor que el que sugeriría la pobre -en generalrelación de Brasil con sus vecinos en otros campos (económico, político, cultural, 


\section{Germán Alburquerque F.}

universitario). Basta pensar en la participación de los cientistas sociales brasileños en instituciones como CEPAL o CLACSO.

${ }^{2}$ Por cierto, esto no quiere decir que hayan sido los únicos intelectuales en asumir tales posturas. Podría decirse incluso que son los voceros más destacados de una corriente liberal que, aunque minoritaria, responde a una tradición de larga data y vigencia en el pensamiento latinoamericano.

${ }^{3}$ Las ideas aquí analizadas corresponden al periodo 1950-1991 y se han excluido, por tanto, aquellas reflexiones elaboradas con posterioridad al año 91 . Este trabajo se enmarca en uno más amplio, referido a los intelectuales latinoamericanos y su participación en la Guerra Fría, que desarrollo como tesis doctoral.

${ }^{4} \mathrm{El}$ nombre oficial del Congreso no incluye el "Antifascistas", pero la tradición lo ha recordado así. El primer Congreso se celebró en París el año 1935.

${ }^{5}$ Con motivo de los 50 años del Congreso se celebró en Valencia el Congreso Internacional de Intelectuales y Artistas, que fue presidido por Octavio Paz y que esta vez sí contó con Mario Vargas Llosa entre sus más inquietos participantes.

${ }^{6}$ Reconoce que muchos intelectuales, incluso él, fueron seducidos por el leninismo, pero algunos se obstinaron en seguir las falsedades del sistema hasta "que perdieron el alma", aludiendo a Paul Eluard, Louis Aragon y Pablo Neruda (PAZ, 1981e, p. 260-261).

${ }^{7}$ La revista Vuelta, dirigida por Octavio Paz, fue quizás la instancia donde más socializaron, pues el peruano no sólo publicó varias veces ahí, sino que se sumó al consejo de colaboración de la revista en 1986.

8 "Los campos de concentración soviéticos" apareció en Sur, (Buenos Aires), 197, marzo 1951 (escrito en París en octubre de 1950). Se reproduce en El ogro filantrópico. Sobre la tendencia antisoviética de la revista Surver King, 1989, p.169.

${ }^{9}$ El Encuentro Internacional de Poetas programado en México también fracasa: además de Paz se restan Neruda, Nicolás Guillén y el soviético Yevgueni Yevtushenko.

${ }^{10} \mathrm{El}$ tema de las dictaduras latinoamericanas también provocó polémica, y aquí fue más bien Paz el acusado, por su supuesta indulgencia respecto a la represión militar, la que contrastaba con la dura denuncia que aplicaba a dictadores de otros lares. Paz quisiera, por su parte, que en el ataque se incluyera a toda clase de dictaduras, esto es, las de Camboya, Checoslovaquia, Albania, Cuba, Bulgaria y Corea del Norte. Afirma también que en moral política no hay cerca ni lejos, correspondiendo pues oponerse ya sea a un Pinochet o Videla tanto como a Estados Unidos por Vietnam y a Cuba por Angola.

${ }^{11}$ Otra versión lo recuerda como "Reagan, rapaz, tu títere es Octavio Paz". Por una cuestión de métrica, me he inclinado por "amigo" y no "títere", aunque ésta es una imagen más potente.

Anos 90, Porto Alegre, v. 16, n. 29, p.261-290, jul. 2009 
${ }^{12}$ En una situación análoga Octavio Paz esgrimía el mismo argumento: su rechazo a las dictaduras militares.

${ }^{13}$ En una ocasión que el Congreso norteamericano aprobó una remesa de 100 millones de dólares al grupo contrarrevolucionario, el novelista protestó airadamente calificando el hecho como una intolerable agresión de un país poderoso contra la soberanía de un pequeño país. Lo cuenta en "Carta a Günter Grass", Vuelta, (México), 117, agosto 1986, 58.

${ }^{14} \mathrm{El}$ original es de Marcha, (Montevideo), marzo 1966.

${ }^{15}$ Original en Marcha, (Montevideo), junio 1967.

${ }^{16}$ En la Praga de Dubcek, explicaba el novelista, se entrevió "un socialismo que reconciliaba realmente las ideas de justicia y libertad. Allí había una gran diversidad de opiniones, se respetaban las distintas opciones, el voto volvía a tener una eficacia real, las asambleas no eran una ficción sino una realidad viva" (TORRES, 1986, p. 275, entrevista de 1975).

${ }^{17}$ Detalles del viaje y de sus impresiones no he encontrado; además, las pocas luces que entrega figuran en entrevistas realizadas más de quince años después.

${ }^{18}$ Consultado por si ese mismo fenómeno se da en el capitalismo, dice que éste también crea privilegios tremendos, pero sólo muy pocos poseen esa superioridad tan absoluta. Reconoce sí que en la URSS se resolvían y resuelven las necesidades básicas de las personas.

${ }^{19}$ Original en Caretas, (Lima), octubre 1968.

${ }^{20}$ La interpelación la hacía extensiva a los "mediocres" partidos comunistas de América Latina.

${ }^{21}$ Según Vargas Llosa, estas palabras las escribió Julio Cortázar en un periódico español hacia 1983/4 (SETTTI, 1989, 34).

\section{Referências}

KING, John. Sur. Estudio de la revista argentina y de su papel en el desarrollo de una cultura. 1931-1970. México: FCE, 1989.

MARRAS, Sergio. América Latina. Marca registrada. Barcelona: Ediciones B-Andrés Bello, 1992.

MICHNIK, Adam. "Optimismo de la Historia. Entrevista con Mario Vargas Llosa”, 1997, http://www.jornada.unam.mx/1997/05/18/sem-adam.html

PAZ, Octavio. Corriente alterna. México: Siglo XXI, 1967.

Anos 90, Porto Alegre, v. 16, n. 29, p.261-290, jul. 2009 


\section{Germán Alburquerque F.}

. Los campos de concentración soviéticos (1951). In: El ogro filantrópico: historia y política 1971-1978. Barcelona: Seix Barral, 1981. [a]

. Debate: presente y futuro de México (1972). In: El ogro filantrópico: historia y política 1971-1978. Barcelona: Seix Barral, 1981. [b]

. El parlón y la parleta (1973). In: El ogro filantrópico: historia y política 19711978. Barcelona: Seix Barral, 1981. [c]

. Los centauros de Santiago (1973). In: El ogro filantrópico: historia y política 1971-1978. Barcelona: Seix Barral, 1981. [d]

. Polvos de aquellos lodos (1974). In: El ogro filantrópico: historia y política 1971-1978. Barcelona: Seix Barral, 1981. [e]

. El espejo indiscreto (1976). In: El ogro filantrópico: historia y política 19711978. Barcelona: Seix Barral, 1981. [f]

. La libertad contra la fe (1978). In: El ogro filantrópico: historia y política 1971-1978. Barcelona: Seix Barral, 1981. [g]

. El ogro filantrópico (1978). In: El ogro filantrópico: historia y política 19711978. Barcelona: Seix Barral, 1981. [h]

- Premio de la Paz de los Editores y Libreros Alemanes 1984. Bonn: Inter Nationes, 1985.

. Tiempo nublado. Buenos Aires: Seix Barral, 1990 (1986).

PAZ, Octavio; ORFILA, Arnaldo. Cartas Cruzadas. México: Siglo XXI, 2005.

PONIATOWSKA, Elena. Octavio Pa\%. Las palabras del árbol. Barcelona: Lumen, 1998.

RODRÍGUEZ LEDESMA, Xavier. Escritores y poder. La dualidad republicana en México, 1968-1994. México: UPN, 2000.

SETTI, Ricardo. A. Sobre la vida y la política. Diálogo con Vargas Llosa. Ensayos, conferencias. Buenos Aires: InterMundo, 1989.

TORRES FIERRO, Danubio. Memoria phral: entrevistas a escritores latinoamericanos. Buenos Aires: Sudamericana, 1986.

VARGAS LLOSA, Mario. Una insurrección permanente (1966). In: Contra viento y marea (1962-1982). Buenos Aires: Sudamericana-Planeta, 1985. [a]

. La censura en la URSS y Alexandr Solzhenitzin (1967). In: Contra viento y marea (1962-1982). Buenos Aires: Sudamericana-Planeta, 1985. [b]

. El socialismo y los tanques (1968). In: Contra viento y marea (1962-1982).

Buenos Aires: Sudamericana-Planeta, 1985. [c]

Anos 90, Porto Alegre, v. 16, n. 29, p.261-290, jul. 2009 
El pensamiento político de Octavio Paz y Mario Vargas Llosa...

Ganar batallas, no la guerra (1978). In: Contra viento y marea (1962-1982).

Buenos Aires: Sudamericana-Planeta, 1985. [d]

. La cultura de la libertad, la libertad de la cultura. Santiago: Fundación Eduardo Frei, 1985.

Recebido em 15/03/2009

Aprovado em 01/06/2009

Anos 90, Porto Alegre, v. 16, n. 29, p.261-290, jul. 2009 